\title{
Phytochemicals and antioxidant activity in four varieties of head cabbages commonly consumed in China
}

\author{
Ying Liang ${ }^{1}$, Yi Li ${ }^{2}$ Liujuan Zhang ${ }^{1}$ and Xianjin Liü ${ }^{*}$
}

\begin{abstract}
Head cabbage (Brassica oleracea var. capitata) is a cruciferous leafy vegetable consumed commonly in China. It has been suggested that diets rich in cabbages play an important role in disease prevention. The phytochemicals as well as antioxidant activity of four typical varieties of head cabbages in China were systematically investigated. Sinapic acid was the most abundant phenolic acid in all samples followed by iso-ferulic acid. Most phenolic acids in red head cabbage were significantly higher than in other head cabbages. The $5-\mathrm{CH}_{3}-\mathrm{H}_{4}$ folate contents in all samples were much higher than folate. Conical head cabbage contained the highest amount of folic acids while red head cabbage had the lowest. Cyanidin was the only anthocyanidins found in red head cabbage with the

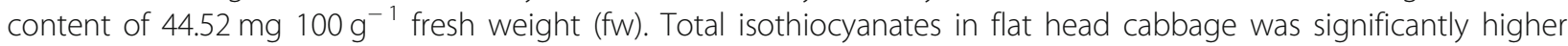
than other head cabbages. Red head cabbage had the significant the highest level of total phenolics and flavonoids with the values of $153.94 \mathrm{mg}$ gallic acid equivalents. $100 \mathrm{~g}^{-1}$ and $51.32 \mathrm{mg}$ rutin equivalents.100 g $\mathrm{g}^{-1}$, respectively, while flat head cabbage had the lowest level. Red head cabbage exhibited the highest antioxidant activity as measured by 1, 1-diphenyl-2-picryl-hydrazyl (DPPH) and 2, 2'-azino-bis (3-ethylbenzothiazoline-6-sulfonic acid) diammonium salt (ABTS) radical scavenging and ferric ion reducing antioxidant power (FRAP) assays with the values of $69.82,87.23 \%$ and 0.53 , respectively. The study suggests that different varieties of head cabbages have different nutritional advantages, and provides useful information to recommend the right head cabbages for consumers.
\end{abstract}

Keywords: Head cabbage, Phytochemical, Antioxidant activity, Phenolic acid, Folic acid

\section{Practical application}

This study provides a meaningful reference for consumers to choose the right head cabbages. Different consumers need different nutrients based on their physical condition. The study substantiated that the different varieties of head cabbages have their own nutritional advantages and it is useful for recommending the right head cabbages for different consumers. It is also useful for farmers to plant the head cabbages with high contents of phytochemicals and antioxidant activity. Among the varieties of head cabbages, red head cabbage had the highest contents of phenolic acids, anthocyanins, total phenolics and flavonoids, as well as the highest antioxidant activity; conical head cabbage

\footnotetext{
* Correspondence: lyjaas@163.com

${ }^{2}$ Institute of food safety and nutrition, Jiangsu Academy of Agricultural

Sciences, Zhongling Street 50, Nanjing 210014, China

Full list of author information is available at the end of the article
}

contained the highest amount of folic acids; flat head cabbage had the highest level of total isothiocyanates from precursor compounds.

\section{Introduction}

Cabbages have proven to be beneficial for health by numerous epidemiological and clinical studies (Podsędek 2007; Cartea and Velasco 2008). High intake of cabbages for consumers could reduce the risk of degenerative diseases, agerelated chronic illnesses (Kris-Etherton et al. 2002) and several types of cancer (Wang et al. 2004; Björkman et al. 2011). The presence of vitamins, provitamins, such as folic acids, and a wide variety of phenolic substances and organosulfur compounds are considered to be contributory factors (Khanam et al. 2012; Cartea and Velasco 2008). Phenolic substances are correlated with the antioxidant activity in many studies (Leja et al. 2010), cabbages have also proved to

(c) The Author(s). 2019 Open Access This article is distributed under the terms of the Creative Commons Attribution 4.0 International License (http://creativecommons.org/licenses/by/4.0/), which permits unrestricted use, distribution, and 
have higher antioxidant activity than many other vegetables such as capsicum, carrot, cucumber, gourd and so on (Isabelle et al. 2010).

There are many reports about the phenolic substances and antioxidant activity of cabbage, many of them have focused on the Chinese cabbage or the red cabbage (Ahmadiani et al. 2014). Seong et al. (2016) studied the antioxidant capacities and polyphenolics of Chinese cabbage leaves, Watanabe et al. (2011) investigated the polyphenol content and antioxidant activity of orangecolored Chinese cabbage. Mizgier et al. (2016) reported the characterization of phenolic compounds and antioxidant properties of red cabbage. Leja et al. (2010) found phenolic compounds as the major antioxidant in red cabbage. Nonetheless, the systematic analysis of phytochemicals in cabbages and the comparisons between the different cabbage varieties were limited.

Head cabbage (Brassica oleracea var. capitata) considered to be originated from China, has been cultivated for a long period (King and Zhang 1996). They play an important role in the diet in Asian countries, especially in China. The production of cabbages and other brassicas were more than 33.88 million tons in China in 2016, it is almost $20 \%$ of total vegetable production according to the Food and Agriculture Organization of the United Nations. The head cabbage commonly consumed in China can be classified into four groups based on the shape and color: red head cabbage (Brassica oleracea var. capitata f, rubra), conical head cabbage (Brassica oleracea var. capitata $f$, acuta), ball head (round head) cabbage (Brassica oleracea var. capitata $f$, alba), and flat head (drum head) cabbage (Brassica oleracea var. capitata $f$, linn).

The present study selected four varieties of head cabbage mentioned above and investigated the phytochemicals and antioxidant activity. The total polyphenol content, total flavonoid content, phenolic acids, folic acids, and total isothiocyanates were determined to clarify the phytochemical profiles. The antioxidant activity were evaluated using DPPH, ABTS and FRAP assays based on their simplicity and widespread application (de Camargo et al. 2019). The findings of this research will improve the understanding of nutrition of head cabbages for food nutritionists and consumers.

\section{Materials and methods Reagents}

The standards of phenolic acids, cyaniding 3-glucoside, folic acids and rutin, 1, 1-diphenyl-2-picryl-hydrazyl $(\mathrm{DPPH}), 2,2$ '-azino-bis (3-ethylbenzothiazoline-6-sulfonic acid) diammonium salt (ABTS) and 2, 4, 6-tris (2-pyridyl)-S-triazine (TPTZ) of analytical grade were obtained from Sigma-Aldrich Co. (St. Louis, MO, USA). Formic acid, hydrochloric acid, benzenedithiol, dichloromethane, ferric chloride and Folin-Ciocalteu's phenol reagent were purchased from Sinopharm Chemical Reagent Co. (Shanghai, China). Methanol and acetonitrile of high performance liquid chromatography (HPLC) grade were from Anpel Laboratory Technologies Inc. (Shanghai, China). Water was purified in a Milli-Q water purification system (Millipore, Burlington, MA, USA).

\section{Instruments}

Phenolic acids were determined by Agilent 1200 Series HPLC (Agilent, CA, USA) and Agilent 6410A triple quadrupole mass spectrometer coupled with Agilent G1948B Electrospray Ionization (ESI) (Agilent, Santa Clara, CA, USA). Agilent 6410 Quantitative Analysis data processing software was used to employ the data. Folic acids and total isothiocyanates were determined by Agilent 1200 Series HPLC equipped with diode-array detector (Agilent, Santa Clara, CA, USA). The absorbance was recorded by Alpha1506 ultraviolet and visible spectrophotometer for the determination of total anthocyanins, phenolics, flavonoids and antioxidant activity (Puyuan, Shanghai, China).

\section{Plant materials and sampling}

Four varieties of head cabbages were purchased from local farm in Jiangsu province, which were major cabbage producing areas. The cabbages were transported under cooling conditions. When arrived at the lab, the cabbages were cleaned and cut into small pieces, frozen in liquid nitrogen and stored at $-80^{\circ} \mathrm{C}$ until use. Sixty-four samples were collected to get results more representative.

\section{Phenolic acids determination}

The sample preparation for determination of free and bound phenolic acids was conducted according to the methods of Zhang et al. (2019). Two grams samples were extracted by $20 \mathrm{~mL}$ of $80 \%$ methanol aqueous solution containing $0.2 \%$ vitamin C. After vortex oscillation for $10 \mathrm{~s}$, the samples were ultrasonicated for $30 \mathrm{~min}$ at room temperature and then centrifuged at $8000 \times$ g for 5 min in a high-speed refrigerated centrifuge. The supernatant was moved to a $50 \mathrm{~mL}$ volumetric flask. After repeating extraction, two supernatants were mixed. Before analysis, the volume of the combined supernatants was adjusted to $50 \mathrm{~mL}$ by adding water and passed through a $0.22 \mu \mathrm{m}$ microporous membrane for free phenolic acids determination. The extraction after centrifugation in above was moved to a $150 \mathrm{~mL}$ conical flask, treated with $20 \mathrm{~mL}$ of $4 \mathrm{M}$ aqueous $\mathrm{NaOH}$, and then purged with $\mathrm{N}_{2}$. The mixed solution was hydrolyzed at $40^{\circ} \mathrm{C}$ for $2 \mathrm{~h}$ in a gas bath with shaking and protection from light. The $\mathrm{pH}$ value was adjusted to 2 by adding $4 \mathrm{M} \mathrm{HCl}$. The mixture was shaken with $20 \mathrm{~mL}$ of $\mathrm{n}$-hexane at room temperature for $20 \mathrm{~min}$ to remove the n-hexane layer. Ethyl acetate $(2 \times 20 \mathrm{~mL})$ was used to 
extract the aqueous layer, and the mixed extracts were concentrated to nearly dry on a rotary evaporator at $35^{\circ} \mathrm{C}$ under reduced pressure. Before analysis, the residue was dissolved in $10 \mathrm{~mL}$ of $50 \%$ methanol/water and passed through a $0.22 \mu \mathrm{m}$ microporous membrane for bound phenolic acids determination.

The phenolic acids were determined by liquid chromatography and electrospray ionization mass spectrometry (HPLC-ESI-MS/MS) on the basis of the method described by Oniszczuk and Olech (2016) with slight modifications. Phenolic acids were separated on XDB $\mathrm{C}_{18}(4.6 \mathrm{~mm} \times 150 \mathrm{~mm}, 5 \mu \mathrm{m})$ at $25^{\circ} \mathrm{C}$. The eluent was consisted of solvent A (water containing $0.1 \%$ formic acid) and solvent B (methanol containing $0.1 \%$ formic acid). The gradient elution program was as follows: $0-1$ min, solvent B from 0 to $5 \% ; 2-4 \mathrm{~min}$, solvent B from 5 to $20 \%$; $8-9.5 \mathrm{~min}$, solvent $\mathrm{B}$ from 20 to $70 \% ; 11.5-15$ min, solvent B from 70 to $5 \%$. The flow rate was $400 \mu \mathrm{L} \cdot \mathrm{min}^{-1}$. Mass spectrometer equipped with an ESI and a triple quadrupole-ion trap mass analyzer. The ESI interface was operated in the negative-ion mode.

\section{Folic acids determination}

Folic acids including $5-\mathrm{CH}_{3}-\mathrm{H}_{4}$ folate $(\mathrm{C} 20 \mathrm{H} 25 \mathrm{~N} 7 \mathrm{O}$, MW 459.46) and folate (C19H19N7O6, MW 441.40) were extracted and analysed following the method from Shohag et al. (2012) with slight modification. Five gram sample was freeze-dried and placed in a $50 \mathrm{~mL}$ centrifuge tube with $25 \mathrm{~mL} 0.1 \mathrm{~mol} \cdot \mathrm{L}^{-1}$ phosphate buffer adding to it, then blew by nitrogen for $15 \mathrm{~s}$ and capped to protect the folic acids. The centrifuge tube was put into water bath at $90^{\circ} \mathrm{C}$ for $10 \mathrm{~min}$, then cooled rapidly on ice and centrifuged at the speed of $26,900 \mathrm{~g}$ for 5 min. After filtration through a $0.2 \mu \mathrm{m}$ membrane, the solution was kept in brown bottle and determined by liquid chromatography. The separation was performed on a column of Zorbax SB-C $18(4.6 \times 150 \mathrm{~mm}, 5 \mu \mathrm{m})$ with $25^{\circ} \mathrm{C}$ of column temperature. The flow rate was $0.4 \mathrm{~mL} / \mathrm{min}$, and the injection volume was $20 \mu \mathrm{L}$. The gradient elution process was started at $6 \%$ acetonitrile $+94 \%$ phosphate buffer and maintained for $5 \mathrm{~min}$, then adjusted to $25 \%$ acetonitrile $+75 \%$ phosphate buffer in $25 \mathrm{~min}$ and maintained for $2 \mathrm{~min}$. The detection wavelength was $285 \mathrm{~nm}$.

\section{Anthocyanidins determination}

Anthocyanidins including cyanidin, delphinidin, pelargonidin, paeonidin, malvidin and petunidin were determined by liquid chromatography (LC). Samples were placed in high-speed freezing grinder and grinded with liquid nitrogen for $1 \mathrm{~min}$. Five grams crushed samples was added with $20 \mathrm{~mL}$ ethanol-water solution (V/V, 3:2) containing of $3 \mathrm{~mol} / \mathrm{L} \mathrm{HCl}$ and extracted by ultrasonic for $40 \mathrm{~min}$, then centrifuged at $26900 \mathrm{~g}$ for $2 \mathrm{~min}$. The upper layer was was hydrolyzed in boiling water bath for $1 \mathrm{~h}$, then cooled immediately and filtered by $0.45 \mu \mathrm{m}$ microporous membrane for LC determination. The chromatographic column is Agilent ZORBAX SB-C18 $(150 \mathrm{~mm} \times 4.6 \mathrm{~mm}, \quad 5.0 \mu \mathrm{m})$, column temperature is $35^{\circ} \mathrm{C}$, the wavelength of UV detector is $525 \mathrm{~nm}$. The eluent was consisted of solvent A (water containing 0.1\% formic acid) and solvent B (acetonitrile containing 0.1\% formic acid). The gradient elution program was as follows: $0-10 \mathrm{~min}$, solvent $B$ from 0 to $20 \% ; 10-20 \mathrm{~min}$, solvent B from 20 to $80 \%$; $20-30$ min, solvent B from 80 to $0 \%$. The flow rate was $800 \mu \mathrm{L} \cdot \mathrm{min}^{-1}$.

\section{Total isothiocyanates determination}

Total isothiocyanates were determined following the method of Totušek et al. (2011) with modifications. Two grams grounded sample were added with $10 \mathrm{~mL}$ deionized water and left to hydrolyze for $3 \mathrm{~h}$ in $40^{\circ} \mathrm{C}$ water bath. $0.5 \mathrm{~mL}$ hydrolysis product were added with $5 \mathrm{~mL}$ methanol, $4 \mathrm{~mL}$ of $0.2 \mathrm{~mol} \cdot \mathrm{L}^{-1}$ sodium borate and $1 \mathrm{~mL}$ of $7 \mathrm{mmol} \cdot \mathrm{L}^{-1}$ benzenedithiol and kept in $65^{\circ} \mathrm{C}$ water bath for $1 \mathrm{~h}$. The reagent was extracted with $5 \mathrm{~mL}$ of dichloromethane and then the upper fraction collected. The procedure was repeated three times. The dichloromethane fractions were combined and filtered through $0.2 \mu \mathrm{m}$ membrane. The total isothiocyanates content was measured using HPLC. The chromatographic system consisted of XDB $C_{18}(4.6 \mathrm{~mm} \times 150 \mathrm{~mm}, 5 \mu \mathrm{m})$ operated isocratically with $70 \%$ methanol in water at a flow rate of $1.0 \mathrm{~mL} \cdot \mathrm{min}^{-1}$ for $10 \mathrm{~min}$. The eluates were monitored with a UV detector at $365 \mathrm{~nm}$. A standard curve was generated from measurements using varying amounts of sulforaphane (SF) to estimate the amount of isothiocyanates in test samples.

\section{Total phenolics determination}

Total phenolic content was determined using the FolinCiocalteau reagent according to previous published procedures (Cai et al. 2004). Data were expressed as milligram gallic acid equivalents (GAE) per gram of fresh weight.

\section{Total flavonoids determination}

Total flavonoid content was measured by a previous method (Seong et al. 2016). The results were expressed as milligram rutin equivalents (RE) per gram of fresh weight.

\section{Antioxidant activity determination Sample preparation}

The head cabbage samples were ground to powder using high speed grinding machine. $100 \mathrm{~mL}$ of $75 \%$ ethanol was mixed with $2 \mathrm{~g}$ sample and refluxed for $30 \mathrm{~min}$. Then the mixture was cooled to room temperature, the 
clear supernatant was got through filtration. The supernatant was stored at $4{ }^{\circ} \mathrm{C}$ and used within $24 \mathrm{~h}$.

\section{$D P P H$ radical scavenging assay}

The DPPH radical scavenging activity was measured using the method described by Borneo et al. (2009) with slight modifications. $3 \mathrm{~mL}$ of $0.003 \%$ ethanol solution of DPPH was mixed with $0.5 \mathrm{~mL}$ extracts and incubated in dark at room temperature for $30 \mathrm{~min}$. The absorbance was measured at $517 \mathrm{~nm}$. The percentage of DPPH radical inhibition was calculated as follows:

$$
\begin{aligned}
& \text { Inhibition of DPPH radical }(\%) \\
& \quad=\left[\left(\mathrm{A}_{\text {control }}-\mathrm{A}_{1}\right) / \mathrm{A}_{\text {control }}\right] \times 100
\end{aligned}
$$

where $\mathrm{A}_{\text {control }}$ is the absorbance of the DPPH solution, and $A_{1}$ is the absorbance of the mixture of DPPH solution and cabbage extract.

\section{ABTS radical scavenging assay}

The ABTS radical scavenging activity was carried out according to Liang et al. (2015). $7 \mathrm{mmol} \cdot \mathrm{L}^{-1}$ ABTS stock solution was reacted with $2.45 \mathrm{mmol} \cdot \mathrm{L}^{-1}$ potassium persulfate to produce the ABTS radical cation. The mixture was stand in the dark for $16 \mathrm{~h}$. $80 \%$ ethanol was used to dilute the ABTS radical cation solution to the absorbance of $0.700 \pm 0.02$ at $734 \mathrm{~nm}$. $0.5 \mathrm{~mL}$ extracts was mixed thoroughly with $2 \mathrm{~mL}$ ABTS radical cation solution (absorbance of $0.700 \pm 0.02$ ) and stood at room temperature for $6 \mathrm{~min}$. Then the UV spectrophotometer was used immediately to record the absorbance at 734 $\mathrm{nm}$. The inhibition percentage of ABTS radical was calculated according to the formula:

$$
\begin{aligned}
& \text { Inhibition of ABTS radical }(\%) \\
& \quad=\left(1-\mathrm{A}_{1} / \mathrm{A}_{\text {control }}\right) \times 100
\end{aligned}
$$

where $\mathrm{A}_{\text {control }}$ is the absorbance of the control solution (containing only ABTS), and $\mathrm{A}_{1}$ is the absorbance in the presence of the cabbage extracts.

\section{Ferric ion reducing antioxidant power (FRAP) assay}

The FRAP assay was performed using the method described by Benzie and Strain (1996). FRAP reagent were consisted of $0.3 \mathrm{~mol} \cdot \mathrm{L}^{-1}$ acetate buffer ( $\left.\mathrm{pH} 3.6\right), 20$ $\mathrm{mmol} \cdot \mathrm{L}^{-1} \mathrm{FeCl}_{3}$ solution and $10 \mathrm{mmol} \cdot \mathrm{L}^{-1} \mathrm{TPTZ}$ solution in $40 \mathrm{mmol} \cdot \mathrm{L}^{-1} \mathrm{HCl}$ in proportions of $10: 1: 1(\mathrm{v} / \mathrm{v} /$ v). The reagent was warmed to $37^{\circ} \mathrm{C}$ in water bath. $200 \mu \mathrm{L}$ FRAP reagent mixed with $5 \mu \mathrm{L}$ sample was incubated at $37^{\circ} \mathrm{C}$ for $10 \mathrm{~min}$. UV spectrophotometer was used to measure the absorbance at $593 \mathrm{~nm}$. All the solutions were prepared before using.

\section{Statistical analysis}

Microsoft Excel was used to perform the statistical analysis. The data were expressed as means of replicate \pm standard deviation. There were 18 samples for red head cabbage and ball head cabbage, respectively, 12 samples for conical head cabbage and 16 samples for flat hand cabbage. If the difference level of $p<0.05$, it was considered significant.

\section{Results and discussion \\ Phenolic acids in cabbages}

The contents of phenolic acids are the sum of free and insoluble-bound phenolic acids and shown in Table 1. Gallic acid, 3, 5-dihydroxy-benzoic acid, chlorogenic acid, caffeic acid, sinapic acid, ferulic acid, iso-ferulic acid and $p$-coumaric acid are added together and expressed as sum of phenolic acids.

The results in Table 1 revealed that sinapic acid was the most abundant phenolic acid in all samples ranged from 635.90 to $12,736.82 \mu \mathrm{g} \cdot \mathrm{g}^{-1} \mathrm{fw}$, followed by isoferulic acid ranged from 415.63 to $3482.20 \mu \mathrm{g} \cdot \mathrm{g}^{-1} \mathrm{fw}$, then 3,5-dihydroxy-benzoic acid and ferulic acid in red head cabbage, ferulic acid and 3, 5-dihydroxy-benzoic acid in other head cabbages. Most phenolic acids except $p$-coumaric acid and chlorogenic acid in red head cabbage were significantly higher than in other head cabbages, especially for 3, 5-dihydroxy-benzoic acid, caffeic acid, ferulic acid and sinapic acid, which represent 10 to 40 -fold difference between red and other head cabbages. Sum of phenolic acids in red head cabbage was of $19,124.60 \mu \mathrm{g} \cdot \mathrm{g}^{-1} \mathrm{fw}$ and significantly higher than other head cabbages. Phenolic acids were no significant differences among flat, ball and conical head cabbages except chlorogenic acid.

There have been several researches about the composition of phenolic acids in Brassica species, but in Brassica oleracea var. capitate groups were limited. Mizgier et al. (2016) identified 21 hydroxycinnamic acid derivatives rather than hydroxylbenzoic acids in red cabbage extract which mainly include $p$-coumaric, ferulic and sinapic acids or their hydrated forms. $p$ coumaric, ferulic and sinapic acids were also found in our study with hydroxylbenzoic acids including gallic acid and 3, 5-dihydroxy-benzoic acid. According to the report of Velasco et al. (2011), sinapic acid was presented in higher quantities in B. napus than in $B$. oleracea crops. Mattila and Hellström (2007) determined the contents of phenolic acids in many vegetables consumed in Finland and found sinapic acid was the dominating phenolic acid in Brassica vegetables with the content almost 10-fold higher in red head cabbage than in ball head cabbage. This finding is in agreement with our studies. 


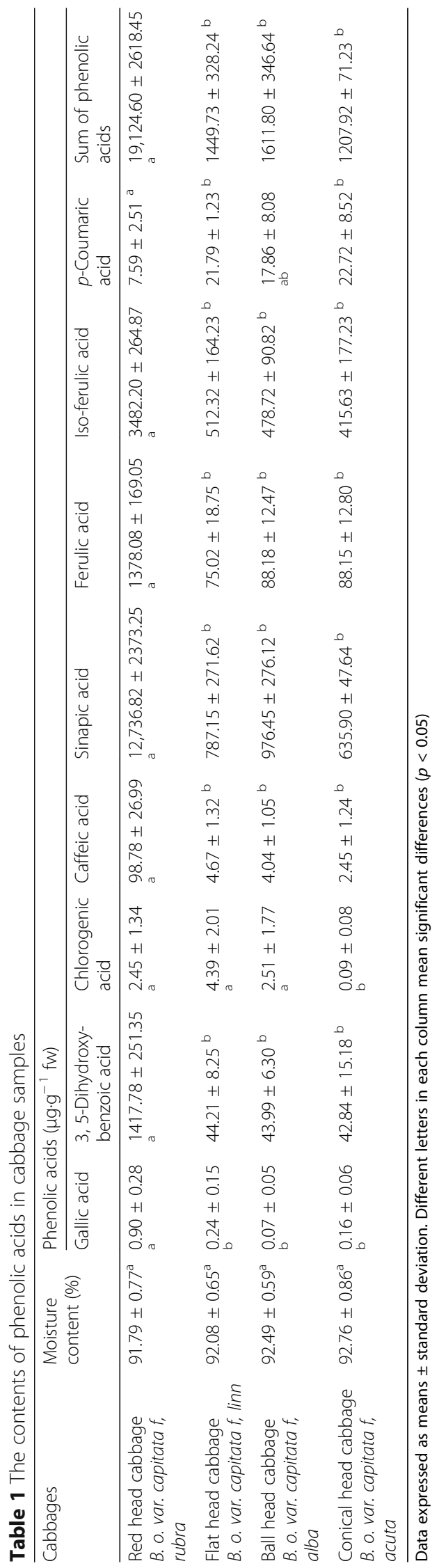




\section{Folic acids in cabbages}

Folic acids in different forms are present in a wide range of food, especially in leafy vegetables (Devi et al. 2008). The contents of $5-\mathrm{CH}_{3}-\mathrm{H}_{4}$ folate $\left(\mathrm{C}_{20} \mathrm{H}_{25} \mathrm{~N}_{7} \mathrm{O}_{6}\right.$, MW459.46) and folate $\left(\mathrm{C}_{19} \mathrm{H}_{19} \mathrm{~N}_{7} \mathrm{O}_{6}, \quad\right.$ MW441.40) which have been proved to be the predominant folate classes in leafy vegetables were determined and presented in Table 2. The $5-\mathrm{CH}_{3}-\mathrm{H}_{4}$ folate contents in cabbages were all much higher than folate. Conical head cabbage was possessed of the highest $5-\mathrm{CH}_{3}-\mathrm{H}_{4}$ folate and folate content which were 80.44 and $41.37 \mu \mathrm{g} \cdot 100 \mathrm{~g}^{-1} \mathrm{fw}$, respectively. Meanwhile, red head cabbage was possessed of the lowest $5-\mathrm{CH}_{3}-\mathrm{H}_{4}$ folate and folate content which were 63.13 and $29.41 \mu \mathrm{g} \cdot 100$ $\mathrm{g}^{-1} \mathrm{fw}$, respectively. Folic acids in conical head cabbage were significantly higher than in red head cabbage. The contents of sum of folic acids ranged from 93.54 to $121.84 \mu \mathrm{g} \cdot 100 \mathrm{~g}^{-1}$ in all cabbages.

According to the report of Shohag et al. (2012), 5$\mathrm{CH}_{3}-\mathrm{H}_{4}$ folate was the major individual vitamer found in cabbage using monoenzyme treatment, which was in line with our study. Holasová et al. (2008) found there was $16 \mu \mathrm{g} \cdot 100 \mathrm{~g}^{-1}$ fw $5-\mathrm{CH}_{3}-\mathrm{H}_{4}$ folate in white cabbage using trienzyme method. Devi et al. (2008) have reported that the total folates in Chinese cabbage (Brassica chinensis.) were $81 \mu \mathrm{g} \cdot 100 \mathrm{~g}^{-1} \mathrm{fw}$. The study of Iwatani et al. (2003) showed the total folate was $68 \mu \mathrm{g} \cdot 100 \mathrm{~g}^{-1} \mathrm{fw}$ in cabbage by microbiological assay. In general, the folic acids values obtained from the current study were higher than the folic acid values reported in the literature. The probable reason for this is not only the variation in variety, season, and climate (Devi et al. 2008), but the differences in analytical procedures (Hefni et al. 2010). There were so many cabbage varieties planted and consumed in China, four varieties in Brassica oleracea var. capitata group were analyzed in the present study. The results indicate that cabbages in green color are better sources of total folates than in red color.
Anthocyanidins, isothiocyanates, phenolics and flavonoids in cabbages

Besides of phenolic acids and folic acids, anthocyanidins, isothiocyanates, phenolics and flavonoids in cabbages were also analyzed and presented in Table 3. Cyanidin was the only anthocyanidins found in red head cabbage with the content of $44.52 \mathrm{mg} 100 \mathrm{~g}^{-1} \mathrm{fw}$. It is in accordance with the results of Wieslaw et al. (2013).

Total isothiocyanates of $7.07 \mathrm{mg} \mathrm{SF} \cdot 100 \mathrm{~g}^{-1}$ in flat head cabbage was significantly higher in other three varieties of cabbages. There were no significant differences in the contents of total isothiocyanates among the red head, ball head and conical head cabbage. Tang et al. (2013) investigated the total isothiocyanate yield from raw cruciferous vegetables consumed in the United States and found a wide range from 0.5 to $77.9 \mu \mathrm{mol} \cdot 100$ $\mathrm{g}^{-1}$ (0.089 to $13.81 \mathrm{mg}$ SF. $100 \mathrm{~g}^{-1}$ ) of total isothiocyanates was observed across the cabbages which may be attributed to genetic and environmental factors. The different varieties of cabbage samples in present study were collected at the same season and the same place. The contents of total anthocyanins in cabbages were in the range of the study of Tang et al. (2013).

Red head cabbage had the significant highest level of total phenolics (153.94 mg GAE. $100 \mathrm{~g}^{-1}$ ) and flat head cabbage had the lowest level (86.64 mg GAE.100 $\mathrm{g}^{-1}$ ). There were no significant difference between ball head and conical head cabbages. Isabelle et al. (2010) analyzed the total phenolic contents of common vegetables in Singapore and found they varied widely across different vegetables even different cabbages. The highest content of total phenolics (186 mg GAE. $100 \mathrm{~g}^{-1}$ ) was found in red cabbage among many varieties of cabbages. Podsędek et al. (2006) reported that red cabbage had the highest total phenolics of 171.36 compared with white cabbage and savoy cabbage. The results of the present study are generally in agreement with previous reports.

The content of total flavonoids in red head cabbage (51.32 mg RE. $100 \mathrm{~g}^{-1}$ ) was significantly higher than

Table 2 The contents of folic acids in cabbage samples

\begin{tabular}{|c|c|c|c|}
\hline \multirow[t]{2}{*}{ Cabbages } & \multicolumn{3}{|c|}{ Folic acids ( $\left.\mu \mathrm{g} \cdot 100 \mathrm{~g}^{-1} \mathrm{fw}\right)$} \\
\hline & 5- $\mathrm{CH}_{3}-\mathrm{H}_{4}$ folate & Folate & Sum of folic acids \\
\hline $\begin{array}{l}\text { Red head cabbage } \\
\text { B. o. var. capitata f, rubra }\end{array}$ & $63.13 \pm 5.63^{b}$ & $29.41 \pm 6.70^{b}$ & $93.54 \pm 5.44^{b}$ \\
\hline $\begin{array}{l}\text { Flat head cabbage } \\
\text { B. o. var. capitata f, linn }\end{array}$ & $64.60 \pm 15.51^{a b}$ & $40.26 \pm 7.07^{a}$ & $103.85 \pm 12.23 \mathrm{ab}$ \\
\hline $\begin{array}{l}\text { Ball head cabbage } \\
\text { B. o. var. capitata f, alba }\end{array}$ & $72.30 \pm 6.50^{a b}$ & $39.72 \pm 4.19^{a}$ & $112.02 \pm 4.97^{\mathrm{a}}$ \\
\hline $\begin{array}{l}\text { Conical head cabbage } \\
\text { B. o. var. capitata } f \text {, acuta }\end{array}$ & $80.44 \pm 4.97^{\mathrm{a}}$ & $41.37 \pm 8.27^{\mathrm{a}}$ & $121.84 \pm 9.78^{a}$ \\
\hline
\end{tabular}

Data expressed as means \pm standard deviation. Different letters in each column mean significant differences $(p<0.05)$ 
Table 3 The contents of anthocyanidins, isothiocyanates, phenolics and flavonoids in cabbages

\begin{tabular}{|c|c|c|c|c|}
\hline Cabbages & 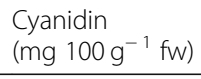 & $\begin{array}{l}\text { Total isothiocyanates } \\
\left(\mathrm{mg} \mathrm{SF} \cdot 100 \mathrm{~g}^{-1}\right)\end{array}$ & $\begin{array}{l}\text { Total phenolics } \\
\left(\mathrm{mg} \text { GAE } 100 \mathrm{~g}^{-1}\right)\end{array}$ & $\begin{array}{l}\text { Total flavonoids } \\
\left(\mathrm{mg} \mathrm{RE} \cdot 100 \mathrm{~g}^{-1}\right) \\
\end{array}$ \\
\hline $\begin{array}{l}\text { Red head cabbage } \\
\text { B. o. var. capitata f, rubra }\end{array}$ & $44.52 \pm 5.16^{a}$ & $2.36 \pm 0.66^{b}$ & $153.94 \pm 5.24^{a}$ & $51.32 \pm 3.48^{a}$ \\
\hline $\begin{array}{l}\text { Flat head cabbage } \\
\text { B. o. var. capitata } f \text {, linn }\end{array}$ & n.d & $7.07 \pm 1.42^{a}$ & $86.64 \pm 11.64^{c}$ & $9.45 \pm 0.42^{c}$ \\
\hline $\begin{array}{l}\text { Ball head cabbage } \\
\text { B. o. var. capitata f, alba }\end{array}$ & n.d & $3.67 \pm 0.95^{b}$ & $125.54 \pm 16.86^{b}$ & $15.26 \pm 2.09^{b}$ \\
\hline $\begin{array}{l}\text { Conical head cabbage } \\
\text { B. o. var. capitata f, acuta }\end{array}$ & n.d & $3.23 \pm 1.49^{b}$ & $119.34 \pm 2.34^{b}$ & $16.48 \pm 1.78^{b}$ \\
\hline
\end{tabular}

Data expressed as means \pm standard deviation. $n . d$ means not detected. Different letters in each column mean significant differences $(p<0.05)$

other three varieties of cabbages. Flat head cabbage had the lowest level of total flavonoids $\left(9.45 \mathrm{mg} \mathrm{RE} \cdot 100 \mathrm{~g}^{-1}\right)$. There were no significant differences between ball head and conical head cabbage. Leja et al. (2010) showed that the total flavonoids were in the range of 38.6 to $41.4 \mathrm{mg}$ quercetin $\cdot 100 \mathrm{~g}^{-1} \mathrm{fw}$ in red cabbage and 4.4 to $6.9 \mathrm{mg}$ quercetin $100 \mathrm{~g}^{-1} \mathrm{fw}$ in white cabbage. The results in the report of Leja et al. (2010) were lower than the present study. It may be not only due to the different varieties of cabbages used in the study but also the different equivalents used in the results.

\section{Antioxidant activity of head cabbages}

The antioxidant activity including DPPH and ABTS radical scavenging and FRAP are shown in Table 4. DPPH. is a stable nitrogen-centered free radical and has been used widely for the determination of antioxidant activity. Red head cabbage was exhibited the highest antioxidant capacities measured by the DPPH and ABTS radical scavenging and FRAP assays with the values of 69.82 , $87.23 \%$ and 0.53 , respectively. The antioxidant activity of flat head, ball head and conical head cabbage were significantly lower than red head cabbage and no significant differences among themselves.

Total phenolic acids in cabbages were significantly correlated with DPPH and ABTS radical scavenging activity and FRAP with the $R^{2}$ of $0.979,0.996$, and 0.971 , respectively $(P<0.05)$. The correlation between total flavonoids and antioxidant activity were also significant with the $R^{2}$ of $0.905,0.954$, and 0.952 , respectively $(P<0.05)$. The correlation between total phenolics and antioxidant activity were relatively low with the $R^{2}$ of $0.479,0.561$, and 0.688 , respectively $(P>0.05)$. The results revealed that total phenolic acids and total flavonoids strongly contributed to the antioxidant activity of head cabbages.

On account of the different modifications of antioxidant assay and different expressions of results even in the same antioxidant assays, it was hard to compare the values of antioxidant activity from different studies. The relative antioxidant activity among the varieties of cabbages can be obtained although there were limited researches on it. Isabelle et al. (2010) compared the hydrophilic oxygen radical absorbance capacity of cabbages including B. o. var. capitata L. (F. rubra) and B. o. var. capitata $L$. and found the capacity of the former was much higher than the latter. Podsędek et al. (2006) evaluated the antioxidant capacity of red and white cabbages by ABTS and DPPH radical scavenging assays and found the capacity of red cabbage were much higher than white cabbage in both assays. These findings are in line with our study.

Oxidative/nitrosative stress (overproduction of free radicals) during hyper-cholesterolemia is a major root cause for the pathophysiology of atherosclerosis and other related cardiovascular diseases (Lahera et al. 2007). The importance of dietary phenolic antioxidants in counteracting cardiovascular diseases is well recognized

Table 4 Antioxidant activity of head cabbages

\begin{tabular}{|c|c|c|c|}
\hline Cabbages & DPPH (Inhibition \%) & ABTS (Inhibition \%) & FRAP (Absorbance) \\
\hline $\begin{array}{l}\text { Red head cabbage } \\
\text { B. o. var. capitata f, rubra }\end{array}$ & $69.82 \pm 0.63^{a}$ & $87.23 \pm 2.75^{a}$ & $0.53 \pm 0.07^{a}$ \\
\hline $\begin{array}{l}\text { Flat head cabbage } \\
\text { B. o. var. capitata f, linn }\end{array}$ & $47.76 \pm 1.23^{b}$ & $28.65 \pm 1.87^{b}$ & $0.24 \pm 0.02^{b}$ \\
\hline $\begin{array}{l}\text { Ball head cabbage } \\
\text { B. o. var. capitata f, alba }\end{array}$ & $44.56 \pm 0.57^{b}$ & $24.36 \pm 1.05^{b}$ & $0.29 \pm 0.02^{b}$ \\
\hline $\begin{array}{l}\text { Conical head cabbage } \\
\text { B. o. var. capitata } f \text {, acuta }\end{array}$ & $43.25 \pm 0.83^{b}$ & $25.48 \pm 2.03^{b}$ & $0.23 \pm 0.04^{b}$ \\
\hline
\end{tabular}

Data expressed as means \pm standard deviation. Different letters in each column mean significant differences $(p<0.05)$ 
(Chiu et al. 2018). For this reason, the intake of red head cabbage is very good for human health.

\section{Conclusion}

This study substantiated that the different varieties of head cabbages have different nutritional advantages and it is useful for recommending the right head cabbages for different consumers. Among the varieties of head cabbages, red head cabbage had the highest contents of phenolic acids, anthocyanins, total phenolics and flavonoids, as well as the highest antioxidant activity; conical head cabbage was possessed of the highest content of folic acids; flat head cabbage had the highest level of total isothiocyanates. The contents of phytochemicals in head cabbages were also influenced by cultivation methods and agronomic factors. There is need to address the relation between cabbage nutrition and planting in future studies.

\section{Abbreviations}

ABTS: 2, 2'-azino-bis (3-ethylbenzothiazoline-6-sulfonic acid) diammonium salt; DPPH: 1, 1-diphenyl-2-picryl-hydrazyl; ESI: Electrospray ionization; FRAP: Ferric ion reducing antioxidant power assays; fw: Fresh weight; GAE: Gallic acid equivalents; HPLC: High performance liquid chromatography; MS: Mass spectrometry; MW: Molecular weight; RE: Rutin equivalents; SF: Sulforaphane; TPTZ: 2, 4, 6-tris (2-pyridyl)-S-triazine

\section{Acknowledgements}

Not applicable.

\section{Authors' contributions}

YLia designed the experiments, analyzed the data of the experiments and drafted the manuscript. YLiu collected the data. LZ helped to collect the data. $\mathrm{XL}$ helped to design the experiments. All authors read and approved the final manuscript.

\section{Funding}

This work was supported by National Key R\&D Program of China (2017YFC1601000) and Agricultural Science and Technology Innovation in Jiangsu Province (cx (18)3054).

\section{Availability of data and materials}

Please contact author for data requests.

\section{Ethics approval and consent to participate}

Not applicable.

\section{Consent for publication}

Not applicable.

\section{Competing interests}

The authors declare that they have no competing interests.

\section{Author details \\ 'Jiangsu Key Laboratory for Food Quality and Safety, Jiangsu Academy of Agricultural Sciences, Zhongling Street 50, Nanjing 210014, China. ${ }^{2}$ Institute of food safety and nutrition, Jiangsu Academy of Agricultural Sciences, Zhongling Street 50, Nanjing 210014, China.}

Received: 14 May 2019 Accepted: 26 July 2019

Published online: 03 September 2019

\section{References}

Ahmadiani, N., Robbins, R. J., Collins, T. M., \& Giusti, M. M. (2014). Anthocyanins contents, profiles, and color characteristics of red cabbage extracts from different cultivars and maturity stages. Journal of Agricultural and Food Chemistry, 62(30), 7524-7531.

Benzie, I. F. F., \& Strain, J. J. (1996). The ferric reducing ability of plasma (FRAP) as a measure of "antioxidant power": the FRAP assay. Analytical Biochemistry, 239(1), 70-76.

Björkman, M., Klingen, I., Birch, A. N. E., Bones, A. M., Bruce, T. J. A., Johansen, T. J., et al. (2011). Phytochemicals of Brassicaceae in plant protection and human health-influences of climate, environment and agronomic practice. Phytochemistry., 72(7), 538-556.

Borneo, R., León, A. E., Aguirre, A., Ribotta, P., \& Cantero, J. J. (2009). Antioxidant capacity of medicinal plants from the province of Córdoba (Argentina) and their in vitro testing in a model food system. Food Chemistry, 112(3), 664-670.

Cai, Y., Luo, Q., Sun, M., \& Corke, H. (2004). Antioxidant activity and phenolic compounds of 112 traditional Chinese medicinal plants associated with anticancer. Life Sciences, 74(17), 2157-2184.

Cartea, M. E., \& Velasco, P. (2008). Glucosinolates in Brassica foods: bioavailability in food and significance for human health. Phytochemistry Reviews, 7(2), 213-229.

Chiu, H. F., Shen, Y. C., Venkatakrishnan, K., \& Wang, C. K. (2018). Popular functional foods and nutraceuticals with lipid lowering activity and in relation to cardiovascular disease, dyslipidemia, and related complications: an overview. Journal of Food Biochemistry, 2, 16-27.

de Camargo, A. C., Biasoto, A. C. T., Schwember, A. R., Granato, D., Rasera, G. B., Franchin, M., et al. (2019). Should we ban total phenolics and antioxidant screening methods? The link between antioxidant potential and activation of NF-kB using phenolic compounds from grape by-products. Food Chemistry, 290, 229-238.

Devi, R., Arcot, J., Sotheeswaran, S., \& Ali, S. (2008). Folate contents of some selected Fijian foods using tri-enzyme extraction method. Food Chemistry, 106(3), 1100-1104.

Hefni, M., Öhrvik, V., Tabekha, M., \& Witthöft, C. (2010). Folate content in foods commonly consumed in Egypt. Food Chemistry, 121(2), 540-545.

Holasová, M. Fiedlerová, V. \& Vavreinová, S. (2008). Determination of folates in vegetables and their retention during boiling. Czech Journal of Food Sciences, 26(1), 31-37.

Isabelle, M., Lee, B. L., Lim, M. T., Koh, W. P., Huang, D., \& Ong, C. N. (2010). Antioxidant activity and profiles of common vegetables in Singapore. Food Chemistry, 120(4), 993-1003.

Iwatani, Y., Arcot, J., \& Shrestha, A. K. (2003). Determination of folate contents in some Australian vegetables. Journal of Food Composition and Analysis, 16(1), 37-48.

Khanam, U. K. S., Oba, S., Yanase, E., \& Murakami, Y. (2012). Phenolic acids, flavonoids and total antioxidant capacity of selected leafy vegetables. Journal of Functional Foods, 4(4), 979-987.

King, T., \& Zhang, J. (1996). Case studies of Chinese economic reform. Washington DC: The World Bank.

Kris-Etherton, P. M., Hecker, K. D., Bonanome, A., Coval, S. M., Binkoski, A. E., Hilpert, K. F., et al. (2002). Bioactive compounds in foods: their role in the prevention of cardiovascular disease and cancer. The American Journal of Medicine, 113(9), 71-88.

Lahera, V., Goicoechea, M., Garcia, V. S., Miana, M., Heras, N. D. L., Cachofeiro, V., et al. (2007). Endothelial dysfunction, oxida-tive stress and inflammation in atherosclerosis: beneficial effects of statins. Current Medicinal Chemistry, 14(2), 243-248.

Leja, M., Kamińska, I., \& Kołton, A. (2010). Phenolic compounds as the major antioxidants in red cabbage. Folia Hortic, 22(1), 19-24.

Liang, Y., Ding, Y., Zhang, L. J., \& Liu, X. J. (2015). Antioxidant activity of Nine Selected Culinary Spices from China. Journal of Northeast Agricultural University (English Edition), 22(1), 50-57.

Mattila, P., \& Hellström, J. (2007). Phenolic acids in potatoes, vegetables, and some of their products. Journal of Food Composition and Analysis, 20(3), 152-160.

Mizgier, P., Kucharska, A. Z., Sokół-Łętowska, A., Kolniak-Ostek, J., Kidoń, M., \& Fecka, I. (2016). Characterization of phenolic compounds and antioxidant and anti-inflammatory properties of red cabbage and purple carrot extracts. Journal of Functional Foods, 21, 133-146.

Oniszczuk, A., \& Olech, M. (2016). Optimization of ultrasound-assisted extraction and LC-ESI-MS/MS analysis of phenolic acids from Brassica oleracea L. var. sabellica. Industrial Crops and Products, 83, 359-363.

Podsedek, A. (2007). Natural antioxidants and antioxidant capacity of Brassica vegetables: a review. LWT - Food Science and Technology, 40(1), 1-11. 
Podsędek, A., Sosnowska, D., Redzynia, M., \& Anders, B. (2006). Antioxidant capacity and content of Brassica oleracea dietary antioxidants. International Journal of Food Science and Technology, 41(s1), 49-58.

Seong, G.-U., Hwang, I.-W., \& Chung, S.-K. (2016). Antioxidant capacities and polyphenolics of Chinese cabbage (Brassica rapa L. ssp. Pekinensis) leaves. Food Chemistry, 199, 612-618.

Shohag, M. J. I., Wei, Y., Yu, N., Lu, L., Zhang, J., He, Z., Patring, J., Yang, X. (2012). Folate Content and Composition of Vegetables Commonly Consumed in China. Journal of Food Science, 77(11), H239-H245.

Tang, L., Paonessa, J. D., Zhang, Y., Ambrosone, C. B., \& McCann, S. E. (2013). Total isothiocyanate yield from raw cruciferous vegetables commonly consumed in the United States. Journal of Functional Foods, 5(4), 1996-2001.

Totušek, J., Třlska, J., Lefnerová, D., Strohalm, J., Vrchotová, N., Zendulka, O., et al. (2011). Contents of sulforaphane and total isothiocyanates, antimutagenic activity, and inhibition of clastogenicity in pulp. Czech Journal of Food Sciences, 29(5), 548-556.

Velasco, P., Francisco, M., Moreno, D. A., Ferreres, F., García-Viguera, C., \& Cartea, M. E. (2011). Phytochemical fingerprinting of vegetable Brassica oleracea and Brassica napus by simultaneous identification of glucosinolates and phenolics. Phytochemical Analysis, 22(2), 144-152.

Wang, L. I., Giovannucci, E. L., Hunter, D., Neuberg, D., Su, L., \& Christiani, D. C. (2004). Dietary intake of cruciferous vegetables, glutathione S-transferase (GST) polymorphisms and lung cancer risk in a Caucasian population. Cancer Causes \& Control, 15(10), 977-985.

Watanabe, M., Musumi, K., \& Ayugase, J. (2011). Carotenoid pigment composition, polyphenol content, and antioxidant activities of extracts from orange-colored Chinese cabbage. LWT - Food Science and Technology, 44(9), 1971-1975.

Wieslaw, W., Dorota, S. N., \& Joanna, T. (2013). Red cabbage anthocyanins: profile, isolation, identification, and antioxidant activity. Food Research International, 51, 303-309.

Zhang, L. Q., Li, Y., Liang, Y., Liang, K. L., Zhang, F., Xu, T., et al. (2019). Determination of phenolic acid profiles by HPLC-MS in vegetables commonly consumed in China. Food Chemistry, 276, 538-546.

\section{Publisher's Note}

Springer Nature remains neutral with regard to jurisdictional claims in published maps and institutional affiliations.

Ready to submit your research? Choose BMC and benefit from:

- fast, convenient online submission

- thorough peer review by experienced researchers in your field

- rapid publication on acceptance

- support for research data, including large and complex data types

- gold Open Access which fosters wider collaboration and increased citations

- maximum visibility for your research: over $100 \mathrm{M}$ website views per year

At $\mathrm{BMC}$, research is always in progress.

Learn more biomedcentral.com/submissions 